\title{
VIBRATIONAL SPECTRA, ASSIGNMENTS AND NORMAL COORDINATE ANALYSES FOR CRYSTALLINE ZIRCONIUM TETRACHLORIDE AND TETRABROMIDE
}

\author{
ROBERT C. TAYLOR* \\ Department of Chemistry. University of Michigan Ann Arbor, MI 48109, U.S.A. \\ and \\ EDWIN M. LARSEN and DAVID R. TAYLOR† \\ Department of Chemistry, University of Winconsin Madison. WI 53706, U.S.A. \\ (Received 17 March 1980; received for publication 22 May 1980)
}

\begin{abstract}
Raman and far-IR spectra have been obtained of crystalline $\mathrm{ZrCl}_{4}$ and $\mathrm{ZrBr}_{4}$. The observed frequencies have been interpreted on the basis of the $C_{2 h}$ symmetry of the Bravais unit cell and have been subjected to a normal coordinate analysis. The interpretation and results are satisfactorily in accord with the $\mathrm{X}$-ray structure.
\end{abstract}

\section{INTRODUCTION}

The structure of solid zirconium tetrachloride is known from X-ray studies [1] to consist of extended chains of distorted octahedra with two bridging chlorine atoms between adjacent zirconium atoms. Although the unit cell possesses a center of symmetry, the two pairs of bridging chlorine atoms attached to a given zirconium atom are not trans to each other. The factor group symmetry thus is $C_{2 h}$ with two zirconium atoms per unit cell. The X-ray structure of zirconium tetrabromide has not been reported but Krebs in his report on the chloride[1] states that the bromide is isostructural with the chloride.

The zirconium halides have been subjected to a limited amount of spectroscopic study. In the vapor phase the work of Clark et al.[2] indicates that the tetrachloride, tetrabromide and tetraiodide all have the expected tetrahedral form. No complete studies of the liquid phase have been reported although a number of authors [3-6] have examined spectra of the octahedral hexahalide anion $\mathrm{ZrX}_{6}^{2-}$ in different solvents. Prior to the present work only the tetrachloride had been studied in the solid state $[7,8]$. In their IR and Raman study of $\mathrm{ZrCl}_{4}$, Weidlein, Mueller and Dehnicke[7] suggested that a polymeric model with bridging chlorines and an octahedral structure around the zirconium was the most reasonable. However, since their work was prior to the $X$-ray work of Krebs[1] they assumed a $D_{2 h}$ symmetry model and made their assignments accordingly. Quite recently, Brockner and Demiray [8] analyzed and compared the spectra of solid and liquid $\left(\mathrm{ZrCl}_{4}\right)_{n}$. The authors based their frequency assignments on a dimeric model with $C_{i}$ symmetry.

In the present work the Raman and IR spectra of solid zirconium tetrachloride and tetrabromide are reported: Examination of the structure reported by

\footnotetext{
*Author to whom correspondence should be addressed.

+Present address: Department of Chemistry, Colorado State University, Fort Collins, CO80523, U.S.A.
}

Krebs [1] indicated that the use of $\mathrm{C}_{2 \mathrm{~h}}$ symmetry rather than the $D_{2 h}$ symmetry utilized previously provided a more realistic model. Assignments were made with the help of a normal coordinate analysis based on the factor group symmetry.

\section{EXPERIMENTAL}

Zirconium tetrachloride obtained from commercial sources was purified by repeated vacuum sublimation. The tetrabromide was prepared by direct combination of the elements and likewise purified by vacuum sublimation.

IR spectra in the range of $80-500 \mathrm{~cm}^{-1}$ were obtained with a Digilab FTS-20 Fourier transform spectrometer. Samples were in the form of mulls prepared in the dry box and contained between Mylar plates. Raman spectra were obtained from polycrystalline samples using a SPEX Ramalog 4 spectrometer equipped with a Spectra Physics 164 argon ion laser. Excitation utilized the 4880 Angstrom line with power levels of the order of $100 \mathrm{mw}$. Estimated uncertainties in peak positions are approximately $1 \mathrm{~cm}^{-1}$ for well defined peaks.

\section{RESULTS}

The observed IR and Raman fundamentals together with symmetry assignments are listed in Table 1 for the chloride and Table 2 for the bromide. Raman spectra are shown in Fig. I and far-IR spectra in Fig. 2. A factor group analysis based on two $\mathrm{ZrCl}_{4}$ units per Bravais cell and $C_{2 h}$ symmetry predicts the following vibrational structure: $7 A_{g}+8 B_{g}+6 A_{u}+6 B_{u}$. All $g$ vibrations are Raman active and all $u$ are infrared active. One lattice mode is included in the $A_{\alpha}$ class and two in the $B_{g}$ leaving six internal model in each class, three associated primarily with bond stretchings and three with deformations. Stretching frequencies may be expected in the range between 450 and $250 \mathrm{~cm}^{-1}$ when $\mathrm{X}=\mathrm{Cl}$ and between 300 and $150 \mathrm{~cm}^{-1}$ when $\mathrm{X}=\mathrm{Br}$.

In the Raman Spectrum of the chloride, five bands are observed between 220 and $415 \mathrm{~cm}^{-1}$. We conclude either the missing frequency has a very low intensity or one of the observed bands is an accidentally degenerate pair. The latter possibility seems a reasonable likelihood and the assumption appears borne out by the fact that the 
Table 1. Observed and calculated fundamental frequencies, symmetry assignments and potential energy distributions for crystalline zirconium tetrachloride

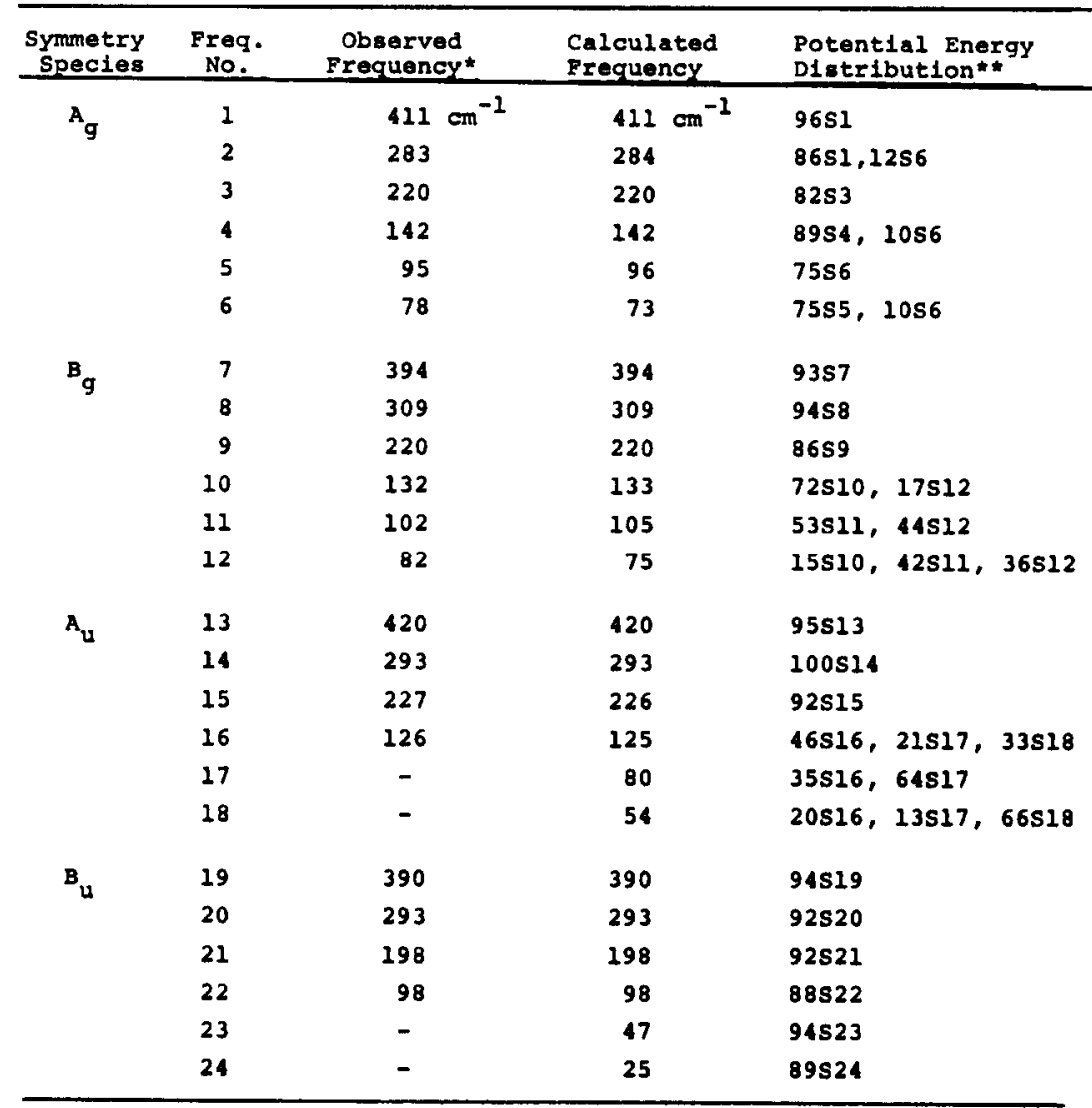

- Gerade Erequencles obeerved in Raman effect, ungerade in infrared

* Contributions lese than 10 percent omitted

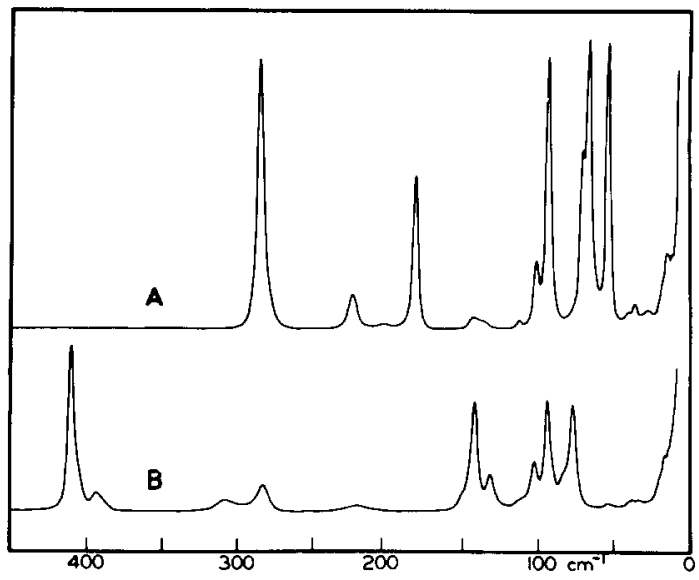

Fig. 1. IR spectra of crystalline $\mathrm{ZrBr}_{4}(\mathrm{~A})$ and $\mathrm{ZrCl}_{4}(\mathrm{~B})$ in the form of Nujol Mulls (resolution $2 \mathrm{~cm}^{-1}$ ).

weak band at $143 \mathrm{~cm}^{-1}$ in the bromide spectrum, which corresponds to the band at $220 \mathrm{~cm}^{-1}$ in the chloride, shows a distinct shoulder at $135 \mathrm{~cm}^{-1}$. We thus infer that the $220 \mathrm{~cm}^{-1}$ band is the degenerate pair, the two frequencies separating slightly when the heavier bromine mass is present. With this identification of the accidentally degenerate band, assignments were completed with the assumptions that the $A_{g}$ modes would be somewhat more intense than the $B_{g}$, and that the stretching of short

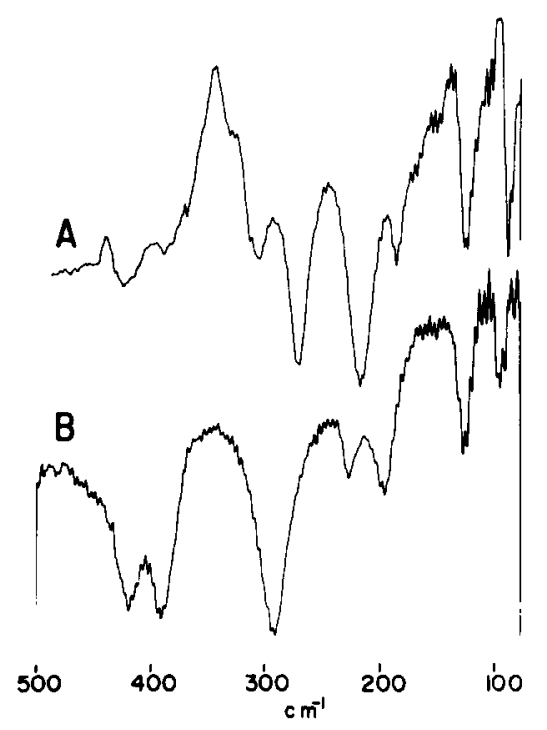

Fig. 2. Raman spectra of crystalline $\mathrm{ZrBr}_{4}$ (A) and $\mathrm{ZrCl}_{4}$ (B) (resolution $0.5 \mathrm{~cm}^{-1}$ ).

$\mathrm{Zr}-\mathrm{Cl}$ bonds would occur at higher frequencies than those of longer bonds. Assignments of the $\mathrm{Zr}-\mathrm{Br}$ stretching modes paralleled those of the chloride. However, for this substance the normal coordinate calculations gave physically unreasonable results unless it 
Table 2. Observed and calculated fundamental frequencies, symmetry assignments and potential energy distributions for crystalline zirconium tetrabromide

\begin{tabular}{|c|c|c|c|c|}
\hline $\begin{array}{l}\text { Symmetry } \\
\text { Specles }\end{array}$ & $\begin{array}{l}\text { Freg. } \\
\text { No. }\end{array}$ & $\begin{array}{c}\text { Observed } \\
\text { Frequency }\end{array}$ & $\begin{array}{l}\text { Calculated } \\
\text { Prequency }\end{array}$ & $\begin{array}{l}\text { Potential Energy } \\
\text { Distribution }{ }^{* \star}\end{array}$ \\
\hline \multirow{6}{*}{$\mathbf{A}_{g}$} & 1 & $285 \mathrm{~cm}^{-1}$ & $285 \mathrm{~cm}^{-1}$ & 8651,1353 \\
\hline & 2 & 183 & 183 & $93 \mathrm{~s} 2$ \\
\hline & 3 & 143 & 143 & 1151,8053 \\
\hline & 4 & 92 & 92 & 8754,1156 \\
\hline & 5 & 66 & 65 & 1154,7456 \\
\hline & 6 & 53 & 45 & 8155,1056 \\
\hline \multirow{6}{*}{$\mathrm{B}_{\mathrm{g}}$} & 7 & 285 & 285 & 8357,1259 \\
\hline & 8 & 223 & 223 & $80 S 8,19 S 12$ \\
\hline & 9 & 135 & 135 & 1457,7459 \\
\hline & 10 & 100 & 98 & $1658,17511,58512$ \\
\hline & 11 & 70 & 73 & $41510,53 s 11$ \\
\hline & 12 & 53 & 52 & $51510,22 s 11,16 S 12$ \\
\hline \multirow[t]{6}{*}{$A_{u}$} & 13 & 305 & 305 & 82513,16515 \\
\hline & 14 & 188 & 188 & 100514 \\
\hline & 15 & 155 & 155 & 17513,81515 \\
\hline & 16 & 90 & 90 & $56 S 16,36 S 18$ \\
\hline & 17 & - & 51 & $39 \$ 16,36 s 17,24 S 18$ \\
\hline & 18 & - & 38 & 55517,37518 \\
\hline \multirow{6}{*}{$\mathbf{B}_{\mathbf{u}}$} & 19 & 270 & 270 & $86 S 19,11521$ \\
\hline & 20 & 218 & 218 & 92520 \\
\hline & 21 & 125 & 125 & 13519,83521 \\
\hline & 22 & - & 58 & $90 \$ 22$ \\
\hline & 23 & - & 28 & 93523 \\
\hline & 24 & - & 10 & 95524 \\
\hline
\end{tabular}

- Gerade frequencies observed in Raman effect, ungerade in Infrared

* Contribution leas than 10 percent omitted

was assumed that the band at $285 \mathrm{~cm}^{-1}$ consisted of an accidentally degenerate pair of frequencies.

In the low frequency $\left(60-150 \mathrm{~cm}^{-1}\right)$ Raman region, a group of six bands is present in the chloride spectrum, one a shoulder on the high side of the band at $78 \mathrm{~cm}^{-1}$. We assign these to the six gerade deformation modes, the three most intense bands again arbitrarily being attributed to the $A_{g}$ modes. In the bromide spectrum, only five bands could be identified, the presumption being that another accidentally degenerate pair is present. The most likely choice appears to be the $53 \mathrm{~cm}^{-1}$ band of the bromide since the shoulder on the corresponding band in the chloride spectrum has disappeared. Three very low frequencies, below about $50 \mathrm{~cm}^{-1}$, were observed in each spectrum and are assigned to the Raman active lattice modes.

Interpretation of the infrared spectrum was complicated by the fact that the lower limit of the spectrometer prevented observations below $80 \mathrm{~cm}^{-1}$ where most of the deformation modes were located. Also, the very striking resemblance between the chloride and bromide spectra found in the Raman case is not as pronounced in the IR further hindering assignments. As in the Raman spectrum of the chloride, only five bands were observed in the range $200-420 \mathrm{~cm}^{-1}$ in the infrared spectrum. We assumed the broad intense band at $293 \mathrm{~cm}^{-1}$ to consist of an accidentally degenerate pair of frequencies, and were thus able to identify six $\mathrm{Zr}-\mathrm{Cl}$ stretching frequencies. This assumption appears reasonable since the band in question is replaced by two bands of lower intensity in the bromide spectrum. Unfortunately, single crystal spectra were not available and the respective symmetry assignments of the two sets of paired frequencies at 420 and $390 \mathrm{~cm}^{-1}$, and 227 and $198 \mathrm{~cm}^{-1}$ therefore has to be made arbitrarily in the absence of any significant guidance from the normal coordinate analysis. In the case of the bromide, six bands were identified in the $\mathrm{Zr}-\mathrm{Br}$ stretching region, although the one at $155 \mathrm{~cm}^{-1}$ was quite weak. Symmetry assignments again were made arbitrarily but matched with those for the chloride. Only two deformation bands were observed in the IR spectrum of the chloride and one in that of the bromide.

\section{Normal coordinate analysis}

A diagram of the two $\mathrm{ZrCl}_{4}$ units showing structure in the unit cell is displayed in Fig. 3. The atom numbers shown in the same figure serve to define the internal coordinates described in Table 3. Symmetry coordinates listed in Table 3 were assembled using the coordinates described by Cyvin [9] for $\mathrm{Nb}_{2} \mathrm{Cl}_{10}$ as a guide and are free of redundancies. A $g$ matrix for the unit cell was constructed using the method outlined by Shimanouchi[10] and transformed into a symmetry coordinate basis using the definitions of the symmetry coordinates. Three types of $\mathrm{Zr}-\mathrm{Cl}$ bonds are present in the $\mathrm{ZrCl}_{4}$ structure based on the X-ray determination [1]: terminal bonds with lengths $d=2.307 \mathrm{~A}$, short bridging 


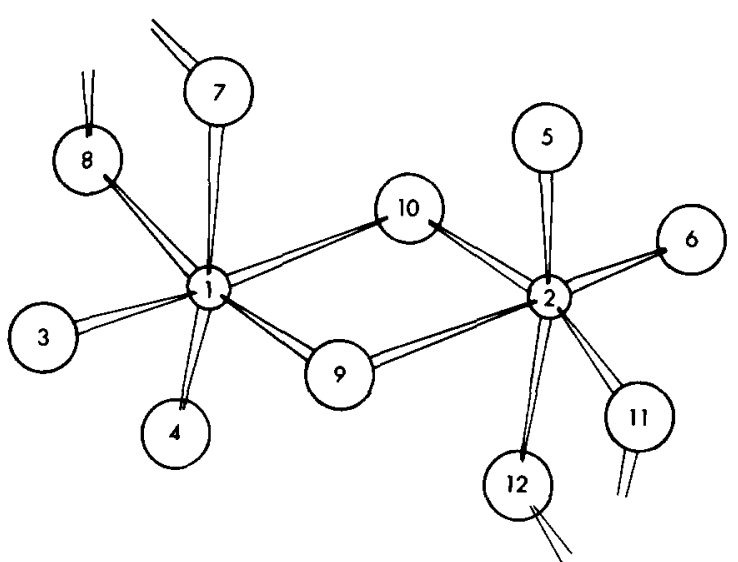

Fig. 3. Schematic diagram showing the atom numbering in the Bravais unit cell of $\mathrm{ZrCl}_{4}$.

bonds with $r=2.498 \mathrm{~A}$, and long bridging bonds with $R=2.655 \mathrm{~A}$. In the crystal, the angles defined by the bonds to zirconium deviate by a few degrees from orthogonal. However, all angles were assumed to be ninety degrees for purposes of the present calculations. Since only two of the eight angles deviate by as much as ten degrees from a right angle, and most are appreciably less, the effect of this approximation was considered minor. In the absence of structural parameters for the bromide, estimated $\mathrm{Zr}-\mathrm{Br}$ bond lengths of $d=2.45 \mathrm{~A}$, $r=2.64 \mathrm{~A}$ and $R=2.80 \mathrm{~A}$ were used with the assumption that the chloride and bromide structures were closely similar. This appears quite reasonable in view of the very marked similarity of the two Raman spectra.

The observed vibrational frequencies for each species were fitted with symmetry force constants using a standard interative least squares program carrying the laboratory designation JACO-3D[11]. Since no isotopic or other supplementary data were available, all offdiagonal constants were constrained to zero and the frequencies were weighted uniformly. In the $A_{u}$ and $B_{u}$ classes, estimated values for the missing deformation frequencies were included but with low weights. No difficulty was encountered in fitting the experimental frequency assignments with diagonal potential function.

Symmetry force constants for the chloride and bromide are shown in Table 4. Potential energy distributions for the two species are given along with the calculated frequencies in Tables 1 and 2. As can be seen from the potential energy distributions, the stretching frequencies are relatively unmixed but the low frequencies tend to be complex. The $\mathrm{B}_{g}$ class frequencies for the bromide particularly were strongly mixed and their description as a group had the poorest correspondence of all the classes to the corresponding class of the chloride. By

Table 3. Valence and symmetry coordinates for crystalline $\mathrm{ZrX}_{4}$

$\begin{array}{cccc}\begin{array}{l}\text { Valence } \\ \text { Coordinate }\end{array} & \text { Defined by atoms } & \begin{array}{c}\text { Valence } \\ \text { Coordinate }\end{array} & \frac{\text { Defined by atoms }}{3-1-9} \\ d_{1} & 1-3 & \phi_{1} & 3-1-8 \\ R_{1} & 1-10 & \phi_{i} & 7-1-10 \\ r_{1} & 1-9 & n_{1} & 7-1-9 \\ \alpha_{1} & 3-1-4 & \omega_{1} & 9-1-10-2 \\ B_{1} & 3-1-7 & \tau_{1} & 10-1-9-2 \\ \delta_{1} & 7-1-8 & \tau_{i} & 10-1-9\end{array}$

No. 2 coordinates are related to No. 1 through inversion

No. 3 coordinates are related to No. 1 through $c_{2}$ rotation

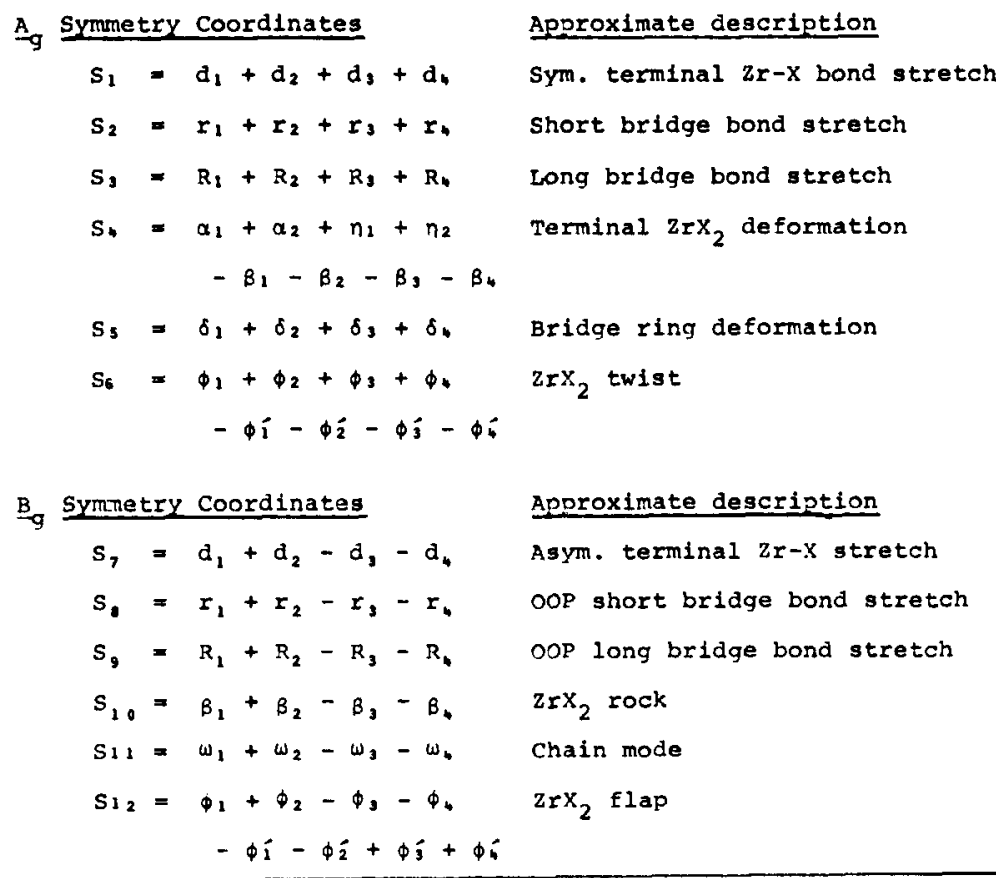


Table 3. (Contd)

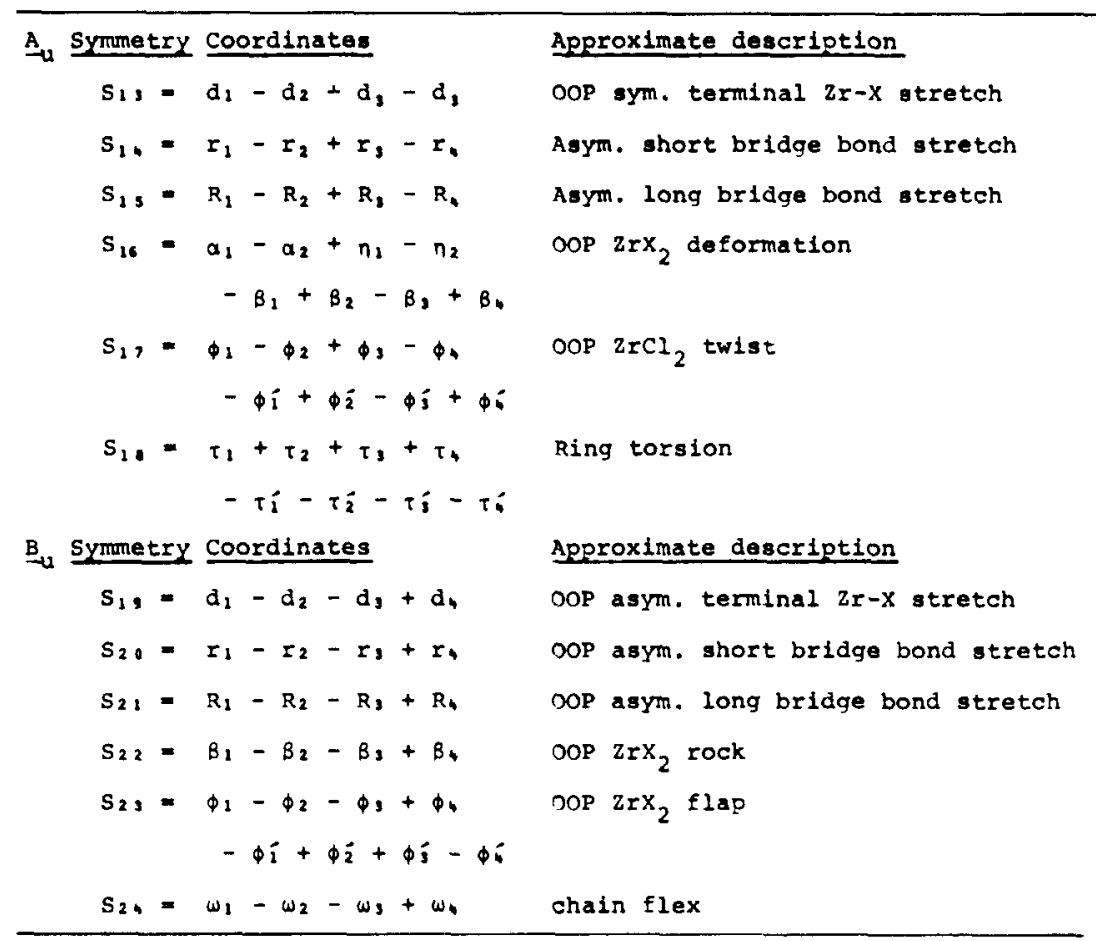

$O O P=$ Out-of-phase, referring to the two $\mathrm{zrX}_{4}$ units in the Bravais cell.

Table 4. Symmetry force constants for crystalline $\mathrm{ZrCl}_{4}$ and $\mathrm{ZrBr}_{4}$

\begin{tabular}{|c|c|c|c|}
\hline $\begin{array}{l}\text { Symmetry } \\
\text { Species } \\
\end{array}$ & Indices & $\mathrm{2rCl}_{4}$ & $\mathrm{zrBr}_{4}$ \\
\hline \multirow{6}{*}{$\mathrm{A}_{\mathrm{g}}$} & 1,1 & 2.420 & 1.803 \\
\hline & 2,2 & 2.481 & 1.485 \\
\hline & 3,3 & .722 & .683 \\
\hline & 4,4 & .591 & .567 \\
\hline & 5,5 & 1.009 & .574 \\
\hline & 6,6 & .455 & .458 \\
\hline \multirow[t]{6}{*}{${ }^{B} g$} & 7,7 & 2.180 & 1.740 \\
\hline & 8,8 & 1.058 & .710 \\
\hline & 9,9 & .765 & .587 \\
\hline & 10,10 & .534 & .494 \\
\hline & 11,11 & .416 & .355 \\
\hline & 12,12 & .445 & .647 \\
\hline \multirow[t]{6}{*}{$A_{u}$} & 13,13 & 2.507 & 2.011 \\
\hline & 14,14 & 1.769 & 1.665 \\
\hline & 15,15 & .831 & .853 \\
\hline & 16,16 & .309 & .399 \\
\hline & 17,17 & $(.350) *$ & $(.234)$ \\
\hline & 18.18 & $(.100)$ & $(.125)$ \\
\hline \multirow[t]{6}{*}{$\mathrm{B}_{\mathrm{u}}$} & 19,19 & 2.161 & 1.608 \\
\hline & 20,20 & .916 & .742 \\
\hline & 21,21 & .637 & .533 \\
\hline & 22,22 & .400 & $(.302)$ \\
\hline & 23.23 & $(.350)$ & $(.262)$ \\
\hline & 24,24 & $(.150)$ & $(.050)$ \\
\hline
\end{tabular}

Units: Stretching constants, ma/Anastrom; bending, ma-ngastrom * Numbers in parentheses corresnond to unobserved frequencies; they were set initially and not adjusted. 
means of the defining equations for the symmetry coordinates (Table 3), the symmetry force constants for the stretching motions can be decomposed into the corresponding valence force constants. This is not possible for the deformation modes due to redundancies. The values for $\mathrm{ZrCl}_{4}$ derived from the $\mathrm{A}_{\mathrm{g}}$ and $\mathrm{B}_{\mathrm{g}}$ symmetry constants are: for the terminal $\mathrm{Zr}-\mathrm{Cl}$ bonds, $f_{d}=$ $2.30 \mathrm{md} / \mathrm{A}$; for the short $\mathrm{Zr}-\mathrm{Cl}$ bridge bonds, $f_{r}=$ $1.27 \mathrm{md} / \mathrm{A}$ and for the long $\mathrm{Zr}-\mathrm{Cl}$ bridge bonds, $f_{R}=$ $0.74 \mathrm{md} / \mathrm{A}$. The stretch-stretch interaction constants are $f_{d d}=0.12, f_{r r}=0.21, f_{R R}=-0.02$, all in $\mathrm{md} / \mathrm{A}$. The corresponding constants for $\mathrm{ZrBr}_{4}$ are (in md/A): $f_{d}=1.77$, $f_{r}=1.10, f_{R}=0.64, f_{d d}=0.03, f_{r r}=0.39$ and $f_{R R}=0.05$.

No previous calculations of force constants for solid $\mathrm{ZrX}_{4}$ were found in the literature and hence there is no ready comparison for the values found in the present work. However, the constants for $\mathrm{ZrCl}_{4}$ in Table 3 are quite similar in magnitude to the symmetry force constants given in Ref.[9] for $\mathrm{Nb}_{2} \mathrm{Cl}_{10}$ which also has an octahedral configuration around $\mathrm{Nb}$ with bridging chlorine atoms. Brisdon, Ozin and Walton[6] have reported a value of $1.54 \mathrm{md} / \mathrm{A}$ for the $\mathrm{Zr}-\mathrm{Cl}$ bond in the anion species $\mathrm{ZrCl}_{6}^{2-}$ and a value of $1.24 \mathrm{md} / \mathrm{A}$ for the $\mathrm{Zr}-\mathrm{Br}$ bond in $\mathrm{ZrBr}_{6}^{2-}$. Again, the comparison is not simple but their values agree very well with those obtained in the present work. Moreover, the ratio of their zirconium-chloride stretching force constant to that of the bromide is essentially the same as that found here. One may conclude from the present study that the vibrational spectra of the two zirconium tetrahalides in the solid state are straightforwardly interpretable in terms of the $\mathrm{X}$-ray structure. The principal uncertainties which exist relate to relative symmetry assignments of neighboring bands, a problem which can be resolved only by single crystal work.

Acknowledgements-The experimental portion of this work was supported in part by the Research Committee of the Graduate School from funds supplied by the Wisconsin Alumni Research Foundation and in part by a NSF Departmental Instrument grant (Grant No. GP-32227) which allowed the purchase of the Raman spectrometer.

\section{REFERENCES}

1. B. Krebs, Angew. Chem. Int. Edn. 8, 146 (1969); B. Krebs, $Z$. Anorg. Allgem. Chem. 378, 263 (1970),

2. R. J. H. Clark, B. K. Hunter and D. M. Rippon, Chem. and Indian 787 (1971); R. J. H. Clark, B. K. Hunter and D. M. Rippon Inorg. Chem. 11, 56 (1972).

3. W. P. Griffith and T. D. Wickins, J. Chem. Soc. A. 675 (1967).

4. D. M. Adams and D. C. Newton, J. Chem. Soc. A. 2262 (1968).

5. J. E. O. Davies and D. A. Long, J. Chem. Soc. A. 2560 (1968).

6. B. J. Brisdon, G. A. Ozin and R. A. Walton, J. Chem. Soc. A. 342 (1969).

7. J. Weidlein, U. Mueller and K. Dehnicke, Spectrochim. Acta 24A, 253 (1968).

8. W. Brockner and A. F. Demiray, J. Raman Spectros. 7, 329 (1978).

9. S. J. Cyvin, H. Hovdan and W. Brockner, J. Inorg. Nucl. Chem. 37, 1905 (1975).

10. T. Shimanouchi, M. Tsuboi and T. Miyazawa, J. Chem. Phys. 35, 1597 (1961).

11. L. H. Jones, R. C. Taylor and R. T. Paine, J. Chem. Phys. 70, 749 (1979). 